\title{
LA APLICACIÓN JUDICIAL DEL DERECHO. PROBLEMAS METODOLÓGICOS: ESPECIAL ABORDAJE DESDE LA PERSPEC- TIVA DE LA TEORÍA DE RONALD DWORKIN EN RELACIÓN CON EL TEMA DE LAS “LAGUNAS DEL DERECHO" Y LOS DENOMI- NADOS "CASOS DIFÍCILES"
}

Daniel Gualberto Gómez ${ }^{1}$

El derecho es un fenómeno complejo, que puede ser abordado para su estudio y comprensión desde distintos puntos de vista, interrelacionados pero diferenciables. Sólo una parte del derecho transita por el mundo de los tribunales, o por el campo de los órganos autorizados (competentes) para decidir controversias jurídicas. Otra parte importante del fenómeno jurídico y de la vida humana en sociedad, transcurre sin mayores controversias ni conflictos relevantes.

La presente investigación, deja de lado gran parte del mundo jurídico que se desarrolla sin controversias ni conflictos, y centra el foco de atención en las disputas que tienen como escenario el ámbito de los tribunales de justicia. Dentro de este marco específico se analizará primordialmente la labor del cuerpo autoritativo que tiene la última palabra en una disputa judicial, o es ungida en la suprema instancia de decisión o resolución de controversias de nuestro Estado.

Esta postura implica dejar fuera del análisis las decisiones de Tribunales internacionales, y de tribunales de menor grado en la jerarquía judicial, aún cuando puedan ser tangencialmente referidos, ya que - es innegable - dichos fallos, tienen injerencia en la vida interna del mismo Estado.

En el campo de la aplicación del derecho, concentraré el foco de la investigación en las decisiones que el más alto tribunal de Justicia de la Nación adopta en los casos en que no existe ninguna norma que prevé la solución (laguna del derecho), o bien cuando los mismos se presentan como de difícil solución según la concepción teórica de Ronald Dworkin. Extendiendo este concepto no del todo claro, al menos desde mi punto de vista, se atenderán además los supuestos en que concurren varias normas de diferente alcance y jerarquía, total o parcial-

${ }^{1}$ Profesor titular de Introducción al Derecho Cátedra A y Profesor Adjunto de Filosofía del Derecho Cátedra B de la Facultad de Derecho y Ciencias Sociales y Políticas UNNE. 
mente contradictorias, para aportar la solución normada. ${ }^{2}$ Eventualmente serán abordados para el análisis algunas decisiones judiciales de clara implicancia política o cuyos efectos tienen proyecciones políticas, a los que denomino "fallos políticos", que podrían tener alguna semejanza con los "asuntos cruciales" en la concepción de Carlos Fernández, esto es, los casos en los que la solución jurídica autoritativa (judicial, legislativa o administrativa) es inevitablemente política y constituye una excepción a lo normativamente previsto en el ordenamiento. Estos casos no se identifican totalmente con la noción del caso difícil esbozada por Dworkin.

Cabe discernir pues, al no haber norma alguna que contemple la cuestión o cuando existen varias normas que concurren para la solución de un caso, o en el supuesto de que los órganos judiciales ejerciten su "arbitrio judicial" ¿de qué modo o bajo qué aspectos relevantes podemos referir a una aplicación del derecho? o, dicho de otro modo, ¿a qué nos referimos cuando decimos que en tales circunstancias se aplica el derecho?

La hipótesis central que pretendo probar sostiene que la CSJN al elaborar una argumentación jurídica o doctrina judicial en los casos de difícil solución, cuando no existe una norma específica que contemple la cuestión, o cuando las existentes son contradictorias, o poco claras, acude a pautas de excesiva latitud (como las que se encuentran consagradas en el preámbulo de la constitución), y por vía de interpretación, la doctrina resultante opera en los hechos como una fuente creadora de derechos.

$\mathrm{Al}$ formular la hipótesis planteada, me propongo también indagar tangencialmente cuáles son los límites formales y materiales que la práctica constitucional del máximo tribunal del país, reconoce como válidos en el ordenamiento jurídico argentino.

No deja de interesar la labor de la Corte en gobiernos considerados "ilegítimos" (o de facto), en tanto que, tomando en cuenta las normas fundamentales del orden jurídico, no hubo mayores cambios normativos, para analizar también si, desde la vigencia del mismo preámbulo constitucional, se dieron pautas presuntamente justificadoras de esa realidad anómala desde la perspectiva jurídica.

${ }^{2}$ Esto implica, según Fernández, que el sistema funciona frecuentemente con un mecanismo de restablecimiento de su equilibrio, que no se corresponde con sus propias reglas de regulación de las relaciones internas, lo que plantea la necesidad de acudir a explicaciones extra sistemáticas, dado que los fundamentos intra-sistemáticos son evidentemente insuficientes; es por eso que el autor habla de "explicaciones" y no de "fundamentaciones", puesto que mal puede fundamentarse dentro del sistema lo que se aparta de sus normas. 
La aplicación del derecho en general, supone una concepción del derecho como un ordenamiento integrado por normas jurídicas que deben ser aplicadas, es decir supone una concepción normativa del derecho.

El derecho es básicamente, para este concepto, un conjunto de normas jurídicas positivas, esto es, "puestas", sancionadas y promulgadas expresamente con la intensión de regir un tramo de la conducta humana. Deben además (estas normas) ser vigentes, lo que equivale a afirmar que no han sido derogadas por otras normas o por una costumbre contraria.

En el proceso de aplicación del derecho realizada por los jueces, el concepto positivista del derecho, supone: a) la existencia previa de una norma que regula el caso; b) la interpretación que también en forma previa a la aplicación realizan los jueces; c) la subsunción de un caso en los preceptos de una o varias normas jurídicas; d) un proceso de argumentación o justificación que haga uso de criterios de razonabilidad; e) la decisión como derivación lógica y coherente del proceso de racionalización o argumentación. ${ }^{3}$

Estos aspectos de la aplicación no se dan químicamente puros, puesto que para la dilucidación de un caso y para la aplicación de la norma, muchas veces se requiere un proceso de selección y verificación de los contenidos normativos, y el empleo de una amplia metodología no del todo jurídicamente elaborada, que lleva (o debería llevar al menos) a una decisión correcta o acertada, válida para todos los casos semejantes.

Esta descripción, excesivamente simple, se ve empañada o dificultada porque en algunas ocasiones, - como señalara anteriormente - no existe norma jurídica alguna que contemple la cuestión en el sistema jurídico, (laguna del derecho) o bien porque aún en el caso de que exista un enunciado normativo contemplativo, la aplicación del mismo controvierte pautas o principios morales, o porque concurren a la solución del caso dos o varias normas de distinta jerarquía que son lógicamente contrapuestas, o bien porque en el ejercicio del arbitrio judicial el juez decide contra legem.

${ }^{3}$ Véase H. L. Hart, "Independencia del derecho y moral", en La filosofia del Derecho, R. Dworkin, Fondo de Cultura Económica, México, p. 37. Para ver cinco argumentos que contribuyen a identificar sentidos de la expresión positivismo: Véase también Carlos M. Fernández, Temas de Filosofia del Derecho, Editorial Moglia, p. 109-110. 
A partir de R. Alexy y últimamente de R. Dworkin se hizo hincapié en que el derecho no es un fenómeno integrado sólo por normas jurídicas, sino también y además, por principios y directrices. ${ }^{4}$

Esta concepción supone una visión más amplia que aquella teoría que sostiene que el derecho está compuesto únicamente de normas jurídicas positivas. Dependerá de la naturaleza y origen que se asigne a los principios o directrices, la elaboración de una concepción genérica (lata) o moderada (estricta) de la relación entre el derecho, la moral y la justicia. Ello así, puesto que en la medida en que los principios constituyan síntesis de enunciados normativos jurídicos positivos (por ejemplo el principio in dubio pro reo o in dubio pro operario) o estén mencionados como referentes de normas jurídicas (el principio de la buena fe) o consagrados en normas constitucionales (como el principio de igualdad o debido proceso), constituyen enunciados distintos de los principios que consagra extrajurídicamente la moralidad o la ética.

Esta concepción más ligada a lo que conocemos teóricamente como iusnaturalismo, sostiene que los jueces en las decisiones de controversias jurídicas y sobre todo en los casos denominados de dificil solución, acuden a pautas de excesiva latitud que no funcionan estrictamente como normas jurídicas sino como un orden de normas extrajurídicas. ${ }^{5}$

La distinción resulta importante para la solución de controversias ya que las fuentes que sustentan las posiciones iusnaturalistas y positivistas son disímiles, y por ende la aplicación del derecho puede diferir en orden a la importancia y jerarquía que cada concepción teórica asigna a las fuentes.

La concepción positivista consagra a la ley como la principal fuente del derecho, y sostiene la independencia del ordenamiento jurídico de la moral. Por ello la ley no sólo será su principal fuente de derechos, sino que le asignará además - mayor jerarquía que las otras fuentes. Para el iusnaturalismo la ley es una fuente importante de derechos, pero puede ser desobedecida o no aplicada en tanto controvierta principios y normas morales o criterios de justicia o equidad. De tal modo la moral por vía de esta concepción se convierte a la vez que en una instancia crítica, en fuente principal de derechos y deberes. ${ }^{6}$

${ }^{4}$ R. M. Dworkin (compilador), Filosofia del Derecho, Fondo de Cultura Económica, México, 1980, Cap. II.

5 Ídem, p. 85.

${ }^{6}$ Ver más sobre el paradigma iuspositivismo/jusnaturalismo en Ariel Álvarez Gardiol, "Epistemología Jurídica", Colección textos jurídicos; Rosario-Argentina, 2010 Capítulo 6; más específicamente p. 313. 
Resulta claro que esta última perspectiva implicará para un positivista decir que en realidad no se aplica "el derecho" de un país, sino normas extrajurídicas que no pueden identificarse con el ordenamiento jurídico de un Estado constituido. Un iusnaturalista replicará que si entendemos por derecho la identificación de las normas jurídicas con las normas morales, o mejor aún, la adecuación de las primeras a los contenidos de las segundas, resultará evidente que, en este sentido, al aplicar normas morales se estará aplicando igualmente "el derecho".

La "teoría crítica" del derecho ha adquirido en los últimos tiempos una importancia y un vuelo inusitado;

Es importante en tanto atribuye relevancia al sentido sociopolítico del derecho, es decir, una plena eficacia al discurso que cuestione el tipo de justicia expuesto por cualquier ordenamiento jurídico. Se debe entonces desprender una formulación aceptable y satisfactoria como discurso que insista en el sentido ideológico del derecho, en la medida en que éste sea responsable de prescripciones normativas desvirtuadas por las relaciones sociales. La estrategia discursiva no niega la "apariencia real" del fenómeno jurídico, sino que procura revelar los intereses y las contradicciones que se ocultan tras una estructura normativa. La crítica se legitima en el momento en que es competente para distinguir, en la esfera jurídica, el "nivel de apariencias" (realidad normativa) de la "realidad subyacente" (o subrayar aquello que no está prescrito pero que existe) ${ }^{7}$

La labor del juez según este criterio teórico consistirá en descubrir ese sentido subyacente que permanece oculto por detrás de las normas jurídicas, y sacarlo a la superficie para que vea luz la intencionalidad de la creación normativa.

Esta controversia verbal sobre el significado y alcance de la expresión derecho se resuelve o diluye parcialmente distinguiendo distintos focos de significado de la misma, ya que tanto empleamos la expresión para hacer referencia a un conjunto de normas jurídicas positivas, o sistema jurídico (derecho objetivo), como también a un conjunto de normas ideales que se pretenden universales (válidas en todo momento y lugar) Derecho natural.

Hecha la distinción y adoptada la concepción o el marco teórico sustentado (positivismo, iusnaturalismo, realismo, criticismo, formalismo, etc.), las

${ }^{7}$ Antonio Carlos Wolkmer, Introducción al pensamiento juridico, Colección en clave de Sur; Primera Edición ILSA, Bogotá-Colombia; 2003, Capitulo 2; p. 32. 
consecuencias de la adopción de una de tales postura implica por ejemplo, para el positivista que sólo tenga en cuenta para la resolución de una controversia las normas legisladas, y para el iusnaturalista, además de las normas legisladas o consagradas positivamente en un ordenamiento, las normas y los principios derivados de una moral crítica. Un jurista realista en la concepción del Ross buscará desentrañar el derecho vigente a través de la labor de la ciencia del derecho, y un jurista crítico los paradigmas subyacentes a las normas jurídicas.

Tampoco resulta claro cuáles son los caracteres distintivos o centrales, que hacen a la aplicación de la palabra "derecho": Cossio y Del Vechio hablaban de conductas, Kelsen de normas, Austin de mandatos, Hart de unión de normas primarias y secundarias, Ross de decisiones judiciales, Alexy de normas y principios, Dworkin de Normas, principios y directrices; Recasén Siches (y la doctrina denominada trialista) de norma, hecho y valor reunidos en un mismo fenómeno jurídico, para no citar algunos pocos autores. Dependerá pues de la adopción de alguna de estas concepciones teóricas la adopción también de metodologías específicas acordes a los criterios teóricos adoptados.

La aplicación del derecho plantea pues varios problemas metodológicos que deben ser analizados en forma previa. La lógica muchas veces constituye la herramienta adecuada para superarlos. Para algunos autores (Alchourrón y Bulygin; "Introducción a la metodología de las ciencias Sociales"; Astrea; 1982) el derecho entendido como sistema normativo o sistema jurídico requiere fundamentalmente el manejo de herramientas deductivas. Para otros, en cambio, en el derecho no basta el manejo de herramientas normativas lógica deductivas sino que, como lo anotan algunas teorías críticas, desde los datos aportados por la realidad de los hechos, el jurista valora y decide normativamente (en ocasiones con criterios de autoridad), tomando datos y objetivos que fijan políticas.

Metodológicamente, en ocasiones, no se pretende partir de definiciones tomadas como dogmas sino de conceptos muy generales para ir hilando los lineamientos del problema. Eduardo Russo en su Teoría General del Derecho siguiendo a Nicolai Hartman observó que la historia del pensamiento filosófico puede seguirse por dos vías: el problemático y el sistemático, según que la visión del conocimiento atienda a cada problema en particular, o al conjunto de los problemas buscando principios cada vez más generales que conformen un sistema de enunciados básicos.

Carlos María Fernández en Temas de Filosofia del Derecho (Ed. Moglia; 2008; pág. 39) luego de explicitar diversas concepciones y funciones del de- 
recho y del conocimiento jurídico, advierte que "debido a la gran variedad de concepciones respecto de la caracterización de funciones que se atribuyen a la dogmática jurídica, la metodología que en ella habrá de emplearse será diferente según la posición que se adopte al respecto". ${ }^{8}$

Algunas corrientes de pensamiento jurídico exponen que un fenómeno tan complejo y variado como es el universo jurídico no puede ser abordado para su estudio con un solo método. No obstante, la Ontología como disciplina filosófica de los objetos postula que para el conocimiento de un determinado tipo de objeto, corresponde un determinado método.

Resulta claro para esta posición que el derecho no es un objeto natural ni metafísico; las normas pertenecen al mundo de los entes ideales y el derecho es un objeto cultural realizado por el hombre para regir la conducta humana en cuanto valor desprendido de su soporte natural (aspecto biológico), e independientemente de sus fines personales (aspecto psicológico). Anida pues en estas concepciones ontológicas la aspiración de desentrañar un único objeto que pueda ser catalogado propiamente de jurídico, y por ende captar la atención del jurista.

Álvarez Gardiol por ejemplo sostiene que "el objeto de la juridicidad, no puede ser otra cosa que la norma jurídica". "La norma jurídica, como objeto de la ciencia del derecho, es una abstracción, y por tanto es una separación de lo fáctico o concreto que sería así una determinación particular de lo abstracto". ${ }^{10}$

Resulta extraño - ha apuntado Fernández- que si el objeto específico del conocimiento jurídico son sólo las normas, como separadas de sus presupuestos y elementos sociológicos o éticos y se caracterizan sus relaciones como imputativas y lógicas - no obstante sostenerse que en el lenguaje prescriptivo no se puede predicar la verdad o la falsedad - se pueda concebirla al mismo tiempo como perteneciente al campo del conocimiento social. Por otra parte dice este autor, si el objeto fuera la conducta normada (según la concepción de Cossio) seria dificultoso separarlo del campo de la sociología y ámbitos afines. Si fuera un instrumento de dominación de clase (a lo marxista) se hallaría en la esfera de la economía y de la política. Si constituyera un medio de lograr la eficiencia en la maximización de recursos (Posner y la escuela del análisis económico del derecho) sería una extensión de la economía. Si vemos al derecho como

${ }^{8}$ Carlos María Fernández, Temas de Filosofía del Derecho, ob. cit.

${ }^{9}$ Álvarez Gardiol Ariel, Epistemologia jurídica, Fundación para el desarrollo de las ciencias jurídicas; Rosario; 2010, p. 347.

${ }^{10}$ Álvarez Gardiol, ob. cit., p. $348 .$. 
una mera expresión del poder, lo llevamos a la ciencia política o a la filosofía política. Si centramos en la argumentación jurídica lo desplazamos al campo de lo que hacen con él los operadores jurídicos. Si se lo concibe como una herramienta tecnológica (según la concepción de Bunge), salimos del contexto del descubrimiento y de la justificación y pasamos al contexto de la mera aplicación, es decir, se lo saca del campo de la ciencia y lo remite al ámbito de la técnica; pero, toda técnica presupone la aplicación de una ciencia (¿cuál?). Tampoco es válida la comparación con la ética, ya que esta - aunque refiere a normas (de otra índole) - que regulan conductas, no es una disciplina de la ciencia, sino de la filosofía. ${ }^{11}$

Otro problema que plantea la aplicación del derecho está relacionado con el discurso jurídico o el proceso de argumentación jurídica (que será motivo de análisis en el capítulo siguiente): esto es, la cuestión relativa a discernir sobre qué bases y principios ha de desarrollarse la argumentación jurídica, cuando esta argumentación se construya para coadyuvar en el proceso y la actividad de aplicación judicial del derecho.

Se debe distinguir en este punto la argumentación jurídica en sentido estricto (reservada para la actividad del juez cuando decide conflictos) de la argumentación jurídica en sentido lato (que abarca la argumentación de los restantes operadores jurídicos: tratadistas del derecho, abogados, legisladores, mediadores, arbitradores). Distintas serán las consecuencias del discurso jurídico y diferirán las formas de argumentación según sea el punto de vista adoptado por los participantes en el mundo del derecho.

Así, no será lo mismo el objeto del discurso del juez, que el propósito del discurso del legislador, del doctrinario del derecho, del abogado, escribano, etc., y hasta del hombre común (destinatario muchas veces de la artillería normativa jurídica) que debe "leer" ese discurso para adaptar (o no) sus conductas a las disposiciones, directivas, recomendaciones o preceptos jurídicos.

En este sentido, como lo puntualiza Nino, hay ciertos arquetipos de conducta de los operadores jurídicos que sin duda, influyen en sus lenguajes y sobre sus posturas en relación al derecho. El lenguaje del juez se encuentra mayormente influido por sus concepciones o convicciones morales, que un abogado quien ve o tiene que vislumbrar la conveniencia de su cliente en función del sistema u ordenamiento jurídico. Para éste, el marco de conductas posibles establecidas por el sistema puede ser combinado con un juego de estrategias para una

${ }^{11}$ Fernández Carlos María; trabajo en preparación facilitado por el autor. 
mejor defensa de los intereses de su clientela. El punto de vista del legislador se encuentra inclinado o determinado por la posibilidad de construir mundos jurídicos "posibles", para materializar de la mejor manera el bienestar común. La creación del derecho se encuentra pues en este operador, en la frontera de la política, en tanto que el ideario de sistema no será más que una expresión del poder. (Por ejemplo, la creación de normas jurídicas que hagan factible la concreción normativa de una directriz que establezca como meta la ordenación y disminución de los accidentes de tránsito).

Cualquiera sea el punto de vista metodológico que se adopte, resulta obvio que para aplicar el derecho (entendido como sistema de normas) se debe previamente interpretarlo. Son dos operaciones distintas: La aplicación judicial del derecho supone otra manera de hacerlo vigente (la pauta de la vigencia de una norma jurídica primeramente lo da el núcleo de gente a quien se encuentra dirigida la norma, y su mayor o menor acatamiento al sentido de su disposición), en cambio, la interpretación consiste en determinar el sentido y el alcance de una norma jurídica, y constituye indefectiblemente una actividad previa a la aplicación.

La eficacia de una norma jurídica implica que sus destinatarios o agentes a quienes va dirigida, la cumplan, o en caso de incumplimiento los jueces o los órganos de aplicación la hacen cumplir.

La aplicación judicial del derecho supone además, la intervención de un órgano competente en una disputa o controversia jurídica sometida a su decisión. En este proceso, es lugar común - por lo conocida y reiterada - la aseveración de que la aplicación requiere un razonamiento lógico o silogismo en el que la premisa mayor está conformada por la norma jurídica, la premisa menor es la descripción de un caso concreto representado también por hechos concretos, y la conclusión implica la emisión de una decisión o fallo. Este modelo simple ha sido criticado en tanto que - se sostiene - no distingue entre los destinatarios de la ley (o de la norma) jurídica, y los destinatarios del fallo, puesto que - también observa - los destinatarios de la ley son los jueces, y el (o los) destinatarios del fallo son ciertos funcionarios que deben ejecutar la decisión, ${ }^{12}$ de allí que difícilmente la decisión puede constituir una deducción.

No obstante ello, como manifiesta Carlos S. Nino, no es criticable que la aplicación de la norma jurídica pueda asimilarse a un enunciado deductivo

${ }^{12}$ Conf. Hernández Marín, Interpretación, subsunción y aplicación del derecho, Marcial Pons; Barcelona, 1999, p. 217. 
silogístico, sino que lo erróneo es considerar o creer que la decisión extraída de ese razonamiento es mecánica.

Rafael Hernández Marín, analiza alternativas a la concepción lógica de la aplicación del derecho. Una de esas alternativas lo constituye la concepción argumentativa que al igual que la concepción lógica sostiene que existe un camino que lleva de la ley al fallo, pero a diferencia de esta, cree que tal sendero está plagado de elementos retóricos, dialécticos, persuasivos, tópicos, hermenéuticos, y no estrictamente lógico deductivos. Otra, es la concepción semántica, que ha de empezar con una descripción correcta de un caso indiscutible de aplicación de derecho, y lo que tiene que hacer el juez es mostrar con su decisión se ha dado cumplimiento a lo que manda el derecho. ${ }^{13}$

Cualquiera sea el camino a seguir, parece una certeza que para aplicar la norma jurídica, el órgano de aplicación debe previamente realizar una interpretación del sentido y el alcance del enunciado normativo, (cuando no de varios enunciados contenidos en un orden jurídico).

"Interpretar" consiste en conocer por extensión el real significado de un signo o símbolo. Es una parte importante de la semiótica, semiología o semántica, vocablos estos que, (valga paradoja) dependiendo del "intérprete", pueden alcanzar distintos significados.

Toda interpretación implica, en cierto modo, una valoración. La interpretación es un término que posee la ambigüedad conocida como de proceso-producto, ya que puede referir tanto al proceso del conocimiento del significado, como al significado luego de realizado y culminado dicho proceso. Para $\operatorname{Ross}^{14}$ la interpretación constituye la metodología jurídica específica, es decir hay una identificación en este autor, entre la tarea de interpretar y la forma de llevarla a cabo, que para otros, siguen campos separados.

Lo que debe interpretar el jurista depende también del marco teórico desde el cual se posiciona para llevar a cabo la tarea de la interpretación. El resultado de la aplicación del derecho previa interpretación, no podrá tener el mismo contenido ni podrá acudir a igual metodología para quienes difieran sobre el objeto del derecho o del conocimiento jurídico. Por ejemplo, para Carlos Cossio el objeto de la interpretación del jurista son las conductas humanas en interferencia intersubjetiva a cuyo fin acude a ciertos esquemas o standars de interpretación (normas) que se encuentran ubicados en el ámbito de los objetos

${ }^{14}$ Ross Alf, Sobre el Derecho y la Justicia, Eudeba; Buenos Aires, 1977, Capítulo IV. 
ideales. (La conducta, cuando no es meramente una manifestación biológica, pertenece al ámbito de la cultura o de los objetos culturales, tomando en consideración la división del mundo de los objetos según la teoría fenomenológica). Para Kelsen la tarea de interpretación se realiza sobre la base de las normas jurídicas que constituyen juicios de deber ser lógico imputativos y que sirven para normar la conducta como directivas dirigidas a los jueces a fin de que apliquen las medidas coactivas que ellas genuinamente establecen. En tanto técnica de motivación indirecta, los particulares deben deducir el contenido del deber jurídico teniendo en cuenta que tal contenido (del deber jurídico) permitirá evitar el acto coercitivo que representa la sanción en la medida que se verifique la conducta opuesta al acto antijurídico y que es el presupuesto de la aplicación de la sanción. Concretamente el jurista según Cossio evalúa conductas, en tanto que según Kelsen, interpreta normas.

Por otro lado, lo expuesto anteriormente en cuanto al marco teórico que asume quien interpreta, supone además realizar una clasificación de la tarea de interpretación, dado que como bien lo señala Guastini, podemos hablar de interpretaciones en abstracto orientada a los textos, o interpretaciones en concreto, dedicada a los hechos; y tomando en cuenta las actividades a las que apunta la tarea interpretativa en el lenguaje común de los juristas, pueden referirse estos al reconocimiento de un significado (operación si se quiere científica y que supone una descripción), a la decisión (acto voluntario si se quiere de naturaleza política), o a la creación o estipulación de un significado (puede ser la consecuencia de un acto legislativo) ${ }^{15}$

Cuando la referencia se realiza a la aplicación de del derecho, dicha aplicación se asemeja a un acto voluntario de naturaleza política. Para la concepción teórica tradicional en la tarea de aplicación del derecho y en la construcción de la voluntad del Estado a través de las sentencias, inciden ciertos principios ideales (difíciles de constatar en los hechos) que son señalados en general como inherentes a la función jurisdiccional, como por ejemplo: "el juez conoce o sabe el derecho"; "los jueces no pueden dejar de juzgar los casos que son sometidos a sus decisiones bajo el pretexto de insuficiencia u oscuridad de las normas"; "los jueces no pueden crear derechos, sino simplemente reconocerlos y aplicarlos a casos concretos".

${ }^{15}$ Guastini Ricardo, "Distinguiendo"; Estudios de teoría y metateoría del derecho; Gedisa, Barcelona, 1999, p. 206 
La actividad de interpretación constitucional tiene algunas peculiaridades distintivas, pero no es sustancialmente distinta a la tarea general interpretativa. La diferencia - si puede señalarse alguna - reside en la importancia que se le asigna a la interpretación que realizan las Cortes superiores, encargadas del control de constitucionalidad por la implicancia que tiene en las decisiones de los jueces de menor jerarquía que, por convicción, por economía procesal, o por el afán de unificar la jurisprudencia, deben adaptar sus decisiones a lo que establecen los tribunales de máxima jerarquía, y porque indirectamente pueden servir de guía de conducta para los órganos e individuos.

Guastini se pregunta ¿cuál es (si existe) la especificidad de la interpretación constitucional? ¿Qué distingue (en el supuesto de que algo la distinga) la interpretación de la Constitución de la interpretación de otro texto normativo? ¿ $\mathrm{La}$ interpretación de la Constitución es algo distinto a la interpretación de la ley ? $^{16}$

Avanza el autor referido, en la hipótesis de que la interpretación constitucional afecta una o más de las siguientes cosas: a) los agentes (a quienes se dirigen los preceptos constitucionales); b) las técnicas (según se trate de constituciones pactadas, liberales, que exigen una interpretación literal o evolutiva) y c) los problemas específicos de la interpretación constitucional (si hay reconocimiento o creación de derechos, si los preámbulos expresan normas, si hay límites lógicos a la revisión, si las constituciones son completas, no poseen lagunas). Cualquiera sea el punto de vista que se adopte, el problema de la interpretación debe empezar por una tarea adecuada de subsunción del caso en una norma.

La subsunción consiste pues, en una tarea de interpretación para determinar si un caso individual se encuentra comprendido o excluido de las previsiones contenidas en una norma jurídica general.

A tal fin, en primer lugar deben ser conocidos los hechos del caso y en segundo término debe establecerse si tales hechos caen bajo la previsión de una u otra norma jurídica. Por ejemplo: se sabe que todo acto de enajenación de una cosa puede ser hecha a título oneroso o gratuito. Juan hizo entrega de su casa a Pedro; no sabemos si lo hizo a título de venta, donación, comodato, depósito. Si Pedro abonó un precio cierto y determinado en dinero, habrá compraventa; si el precio abonado es irrisorio con respecto al valor real de la cosa habrá donación encubierta; si lo hizo en calidad de préstamo, habrá comodato o préstamo de uso; si la entrega fue realizada en calidad de guarda o cuidado de la cosa con

${ }^{16}$ Guastini Ricardo, ob. cit., p. 287. 
cargo de devolución después de transcurrido un tiempo, habrá depósito.

Según Alchourrón y Bulygin ${ }^{17}$ los problemas de la clasificación o subsunción de un caso individual pueden originarse en dos fuentes distintas a) por la falta de información sobre los hechos relevantes y b) por la vaguedad, ambigüedad, indeterminación de los textos legales. A juicio de estos autores el primer aspecto del problema puede solucionarse con el recurso práctico de recurrir a la prueba indiciaria o a las presunciones. El segundo problema podría mitigarse recurriendo al uso de conceptos técnicos, definiciones explicitas, distinciones terminológicas etc.

Integrar el derecho es una tarea distinta a la de interpretar. Se relaciona con los vacíos legales o con el problema de las lagunas del derecho. Integrar el derecho a una comunidad es vivificarlo o hacerlo vivo en función de pautas culturales o sociales. En esta tarea se toma en consideración tanto las costumbres como la moral positiva. La tarea de integrar el derecho, está más ligada con la aplicación del derecho, tomando en consideración circunstancias presentes y no desde un punto de vista histórico. Por ejemplo se integra el derecho cuando se extiende la utilización del término "correo" contenido o mencionado en una norma jurídica a circunstancias actuales que comprende el correo electrónico, antes inexistente o desconocido como tal; o por ejemplo el término "gestación" a la fecundación in vitro, o manipulación genética, o la expresión "matrimonio" puede ser asimilada a la situación conocida como concubinato o matrimonio de fe. Estas circunstancias llevan a considerar y analizar cuál es la labor o la función del juez, y cuál es la injerencia que puede llegar a tener un juez en el proceso de creación, modificación o transformación del derecho.

El derecho tiene como fin primario la regulación de la conducta del hombre para hacer posible, con cierto orden, la vida en sociedad. Como la complejidad de la trama social y las distintas circunstancias que influyen en la conducta se muestran insuficientes para evitar los conflictos de intereses, aparece el derecho que a través de sus órganos dotados de autoridad, pretende resolver los problemas recurriendo para ello, a pautas normativas que se suponen justas.

Esas pautas de conducta supuestamente justas, constituyen además, guías de actuación para hacer posible entre otros objetivos, la paz social y la convivencia pacífica entre los hombres. La característica primordial del derecho en la solución de los conflictos de intereses, está dada por la recurrencia de sus órganos esta-

${ }^{17}$ Alchourrón y Bulygin, Introducción a la Metodología de las ciencias juridicas y Sociales; Astrea; 1975, p. 61 . 
tuidos e institucionalizados, a la autoridad por un lado y a la coacción por otro.

Cuando se agotan los medios disponibles consensuados o acordados para la solución de conflictos no queda otra alternativa que recurrir a los órganos de los ordenamientos jurídicos institucionalizados, para que brinden la solución de acuerdo con las normas del sistema. Uno de los remedios a las dificultades y problemas que plantea los conflictos de intereses es la implementación de la jurisdicción obligatoria encomendada a los jueces, para que determinen la conducta que es conformada a derecho. ${ }^{18}$

Para que cumpla adecuadamente con su función jurisdiccional el juez por un lado tiene que conocer el derecho o las normas jurídicas del sistema que lo estatuyó como tal, y por otro lado, tiene que conocer los hechos que son sometidos a su función o jurisdicción. Estos requisitos son necesarios pero no suficientes para cumplir con el rol de juzgar, ya que además debe poseer "competencia" para conocer un caso dado, y seguir las normas del procedimiento establecido para arribar a una sentencia válida. Por otro lado, cabe considerar que la sentencia constituye una norma individual que soluciona normativamente un caso, y que se deriva del conjunto de normas generales del sistema.

Finalmente esta creación individual del derecho debe contener los argumentos que llevaron al juez a adoptar su decisión en el caso concreto, o dicho de otra manera la solución individual debe aparecer suficientemente fundado o motivada.

La sistematización de un orden jurídico consiste en una tarea intelectual del jurista que parte de la base de considerar al Derecho como un orden dinámico y coherente de normas jurídicas. Se trata de mostrar de qué manera las distintas normas que integran el ordenamiento jurídico, pese a su jerarquización y distintos contenidos, no están yuxtapuestas sino en cierto modo se complementan formando un sistema homogéneo. Ésta es una concepción formalista que supone además el postulado valorativo de que el derecho debe ser pleno y sin normas contradictorias.

La realidad de los ordenamientos jurídicos muestra que el ideal o el dogma de la completitud y de la coherencia se encuentran lejos de alcanzarse, ya que no sólo existen normas contradictorias o inconsistentes entre sí pertenecientes a un mismo orden jurídico, sino además normas de redacción redundante, algunas

${ }^{18}$ Alchourrón y Bulygin, "Introducción a la Metodología de las ciencias jurídicas y sociales", Astrea; p. 203. 
de las cuales son inoperantes.

Dos normas jurídicas son inconsistentes entre sí cuando ofrecen soluciones distintas y contrapuestas para un mismo caso, y que tienen el mismo ámbito de aplicación. Por ejemplo Una norma que estipule la obligatoriedad de una conducta y otra que prohíbe la realización de la misma conducta. La inconsistencia de normas puede ser total (de manera que la aplicación de una haga inaplicable la otra) o parcial (de manera que puede haber un ámbito de superposición o inclusión de sus ámbitos de referencia (Por ejemplo el término "vehículo" contenido en una norma comprende tanto a los autos como a los camiones, "vehículos de transporte" únicamente a estos últimos).

Dos normas jurídicas son redundantes si disponen la misma solución normativa para el mismo caso. Por ejemplo una norma que prescriba que es obligatorio pagar el impuesto al valor agregado, y otra que diga que se encuentra prohibido dejar de pagar el impuesto al valor agregado.

Una norma jurídica es inoperante cuando es imposible que sea aplicada por razones empíricas o fácticas o por razones lógicas: ejemplo del primer caso sería una norma que dijese "el embarazo de una mujer deberá limitarse a los seis meses a partir del momento de la gestación"; sería lógicamente imposible por superflua aplicar una norma que prescriba "La declaración jurada de bienes deberá ser presentada aunque se carezca de bienes".

La sistematización consiste en encontrar una solución normativa que sea compatible con la totalidad del orden jurídico, sea declarando la inoperancia de las normas para el caso concreto o la prevalencia de una norma sobre otra echando a mano criterios de interpretación y aplicación que hagan hincapié en diferentes circunstancias que caracterizan a la validez normativa: por ejemplo, los criterios interpretativos que expresan que una ley superior debe prevalecer sobre una ley inferior; que una ley especial debe tener preeminencia sobre una ley general; o que una ley posterior deroga a una ley anterior.

Las construcciones jurídicas son frutos de una concepción dogmática del derecho, que considera al derecho entendido como un orden legal o normativo, como sustento de significaciones lógico objetivas desprendidas de la voluntad del legislador que las formuló. Metafóricamente se asigna a la ley una voluntad que nada tiene que ver con la voluntad real o psicológica del legislador creador. La ley jurídica en su relación de coordinación y subordinación sistemática es el instrumento por medio de cual se pueden extraer las soluciones a los problemas planteados por los hechos o por casos posibles. La elaboración de las soluciones a 
los casos posibles que puedan presentarse es una tarea deductiva, lógica, sistemática y racionalmente posible. La Escuela dogmática y su método interpretativo, abandonó la búsqueda del significado de la ley en el método gramatical, o en la intensión del legislador como lo propugnaba la escuela exegética del derecho, para indagar la búsqueda del significado en una estructura superior totalizadora y sistemáticamente estructurada. Las normas aisladas al ser creadas, se integran a la estructura y pueden en virtud de métodos interpretativos perder el sentido original asignado por el legislador. Propugna recurrir a métodos formales lógico deductivos de interpretación, y a teorías jurídicas que eran el resultado de procesos generales de gradual abstracción, que intentaban dar cuenta de la realidad jurídica, del que se deducían principios generales rectores que servían de base sobre todo cuando la solución legal de un caso no se encontraba explícitamente contemplada o no surgía en forma clara. Savigny sostuvo que en la interpretación de la ley debían distinguirse cuatro elementos: el gramatical, el lógico, el histórico y el sistemático, y se encargó de subrayar que no se trataba de cuatro elementos independientes uno del otro, sino complementarios en la búsqueda de la interpretación del texto legal. ${ }^{19}$

\section{Síntesis}

El derecho es un fenómeno complejo que requiere para su comprensión de diversas herramientas de análisis, y la distinción de los planos o materiales de estudio. Al dejar de lado la parte del derecho referida a las conductas sin conflicto (pero que son regulados jurídicamente), se atenderá a las controversias que deben ser resueltas por los órganos judiciales con competencia para emitir decisiones autoritativas, concentrando el foco de atención en las decisiones del órgano superior del poder judicial en los llamados casos difíciles, a fin de corroborar (o no) la tesis que sostiene que en algunos de tales casos, el máximo tribunal aplica las directrices contenidas en el preámbulo de la constitución, sea para reforzar un proceso de argumentación, sea para emitir con tales fundamentos la decisión.

Al tomar como punto de referencia los casos difíciles, se tiene en consideración el marco teórico elaborado por la teoría de Ronald Dworkin sobre el concepto de derecho, y obviamente las consecuencias metodológicas derivadas de tal concepción.

\footnotetext{
${ }^{19}$ Aftalión, Vilanova, Raffo, Introducción al Derecho, Abeledo Perrot; Buenos Aires; 1999, p. 757.
} 
Es evidente que el proceso de aplicación del derecho requiere previamente de una interpretación, (constitucional si se quiere ya que se apunta a una faceta de la Corte Suprema de Justicia de la Nación como Tribunal de garantías constitucionales). La metodología depende del marco teórico que se adopte, aun cuando de manera insoslayable deba acudirse a las subsunciones, sistematizaciones, construcciones jurídicas etc., aspectos estos que en tanto son instrumentos metodológicos de la concepción positivista del derecho se alejan de la teoría que se toma como base en el marco teórico adoptado. 